\title{
Depois da colostomia...vivências das pessoas portadoras
}

Recebido em: 25/10/2011 Aceito em: 15/02/2012

\author{
Clementina Fernandes Sousa ${ }^{1}$
}

Dalila Cunha Brito

Maria Zita Pires Castelo Branco ${ }^{3}$

O estudo inscreve-se numa abordagem qualitativa. Vinte pessoas com colostomia e sete enfermeiros foram entrevistados entre junho e julho de 2009. Pretendeu-se identificar e analisar as percepções sobre a doença, as implicações de uma colostomia na vida das pessoas portadoras e a resposta de enfermagem comunitária. As pessoas colostomizadas têm necessidades próprias e, portanto, a atenção primária pode desempenhar um papel fundamental. A existência de consulta de estomaterapia nos centros de saúde é necessária.

Descritores: Colostomia, Necessidades, Cuidados de Enfermagem.

\section{After colostomy...experiences of patients presenting colostomies}

That is a qualitative study. Twenty patients presenting colostomy and 7 nurses were interviewed from June to July 2009. The aims were to identify and analyze the perceptions about disease, the colostomy implications on the patients' daily life and the community nursing response. Patients presenting colostomy have their own needs and, therefore, community nursing can perform a fundamental role. So that requires enterostomal therapist nursing in health centers.

Descriptors: Colostomy, Needs, Nursing Care.

\section{Después de la colostomía...experiencia de pacientes portadoras}

Se trata de un estúdio com enfoque cualitativo. Se utilizó la entrevista a 20 personas con colostomía y 7 enfermeras, entre Junio y Julio de 2009, con objetivo de identificar y analizar las percepciones sobre la enfermedad, las implicaciones de una colostomía para las personas portadoras y la respuesta de enfermería comunitaria. Las personas tienen necesidades propias y, por lo tanto, la atención primaria puede desempeñar un papel clave y es fundamental la consulta de estoma terapia en los centros de salud.

Descriptores: Colostomía, Necesidades, Atención en Enfermería.

\section{INTRODUÇÃO}

U ma ostomia pode causar profundas mudanças na vida das pessoas e suas famílias, que se manifestam por desajustes físicos, emocionais, sociais e familiares. Os percursos de vida das pessoas com ostomia são resultantes dos significados que lhe atribuem, tendo o enfermeiro um papel mediador, no sentido de prepará-las para a criação do estoma e capacitação para lidar com a nova experiência de vida, facilitando um processo transicional saudável.

Vários estudos afirmam que os cuidados de enfermagem iniciados no pré-operatório acompanhado do trabalho integrado e continuado das equipes de saúde ajudam a melhorar o processo de adaptação em longo prazo e a qualidade de vida ${ }^{(1-3)}$.

\section{METODOLOGIA}

A opção metodológica seguiu uma abordagem qualitativa, de natureza exploratória e descritiva, tendo como objetivos: analisar as percepções das pessoas com colostomia definitiva relativamente a sua doença; analisar as implicações da colostomia em sua vida; identificar necessidades e redes de suporte social e de saúde utilizadas; e identificar os cuidados de enfermagem comunitária prestados.

Participaram 20 pessoas com colostomia definitiva, frequentando a consulta de estomaterapia, com doença clinicamente controlada, e sete enfermeiros de centros de saúde (dois urbanos e cinco rurais) da Unidade Local de Saúde do Alto Minho, EPE, entre junho e julho de 2009. Após a autorização da instituição e concordância dos participantes, foram explicados os objetivos do estudo, garantindo o cumprimento dos aspectos éticos e do respeito pela dignidade humana.

A recolha de informação foi feita através de entrevista semiestruturada com gravação em áudio e posteriormente transcrita na íntegra. Para a análise dos registos, foi utilizada a

1 Enfermeira. Professora-adjunta. Escola Superior de Saúde. Instituto Politécnico de Viana do Castelo, doutoranda em enfermagem - Universidade Católica Portuguesa Porto. E-mail: clementinasousa@ess.ipvc.pt.

2 Enfermeira-chefe. Centro Hospitalar de Vila Nova de Gaia-Espinho. Doutoranda em enfermagem - Universidade Católica Portuguesa.

3 Enfermeira. Professora-adjunta. Escola Superior de Enfermagem de Vila Real. Universidade de Trás-os-Montes e Alto Douro. Doutoranda em enfermagem - Universidade Católica Portuguesa. 
técnica de análise de conteúdo ${ }^{(4)}$, por nos parecer adequada à natureza do fenômeno em estudo, visando a compreender o sentido dos discursos e as significações explícitas e implícitas.

Posteriormente, efetuaram-se leituras flutuantes e aprofundadas da informação, identificando segmentos de texto menores, considerados unidades básicas de análise, que foram agregadas e organizadas em grupos temáticos, por similitude de fenômeno ${ }^{(4,5)}$.

\section{APRESENTAÇÃO E ANÁLISE DE DADOS}

A amostra foi constituída de 12 homens e oito mulheres, com idades entre 50 e 80 anos. Quanto ao estado civil, eram dez casados, sete viúvos e três solteiros, e todos reformados. Esses dados conformam a epidemiologia da doença oncológica colorretal, conducente à principal causa de cirurgia de ostomia em pessoas idosas(6).

Da análise dos discursos emergiram as seguintes categorias: perceções sobre a doença e a ostomia; emergência de necessidades e alterações de vida após a ostomia; respostas das redes de suporte social e de saúde.

\section{Percepções sobre a doença e a ostomia}

Torna-se difícil descontextualizar uma colostomia definitiva da doença oncológica colorretal, uma vez que essa representa sua principal causa. Essa realidade implica que a pessoa tem de enfrentar dois tipos de impacto: o diagnóstico de câncer e o procedimento cirúrgico, acompanhados de sofrimento

"Alguns relatos associam a colostomia ao alívio da dor e à resolução da doença, demonstrando otimismo e esperança: 'Antes, tinha muitas dores, assim não podia viver. (...) agora as dores passaram"' quando os sacos caíam. Agora estou mais conformado" (E1).

Prevalece idêntico conformismo quanto à mutilação física, manifestado por sentimentos de impotência e aceitação de uma realidade que não podem alterar e ou na crença num destino determinado pela vontade de Deus: "Tem de ser, tem de ser, não há volta a dar (E10); Nunca fiz mal a ninguém, mas Deus quis assim, o remédio é aceitar o que Ele nos dá" (E14).

\section{Emergência de necessidades e alterações de vida após a ostomia}

A necessidade de informação pré-operatória emerge em vários enunciados, qualificando de inadequado o tempo e o modo como foram informados: "Gostaria que me dissessem antes, pensei que era só um curativo" (E2); "O cirurgião disse que tinha de ser operado, mas não me informaram o quê (...) não tive tempo para pensar, foi tudo tão rápido" (E16).

A maioria dos participantes enuncia como necessidades pós-alta o apoio psicoemocional e informação sobre a evolução, caraterísticas e cuidados ao estoma, alimentação e vestuário. O acompanhamento pós-alta é defendido por vários autores como facilitador da adaptação em longo prazo e do (re)encontro do sentido da vida ${ }^{(1-3,10)}$.

Embora existam referências de alguns ganhos em saúde (alívio da dor), as perdas e alterações cotidianas são de longe mais significativas.

No domínio psicoemocional, despontam sentimentos de inutilidade, não apenas porque se reconhecem doentes: "Sinto-me um inútil (chora), não me dói nada mas não tenho a saúde que tinha"; mas também porque a ostomia alterou o papel familiar ou profissional: "Deixei de ser a pessoa que mandava em casa" (E9); "Tive que pedir a reforma, é complicado trabalhar assim" (E15).

A maioria evidencia disposição para o autocuidado. Alguns participantes, embora autônomos antes da cirurgia, passaram a ter comportamentos dependentes, delegando o autocuidado a um familiar, sendo as mulheres (esposas ou filhas) as cuidadoras informais: "Vou até o café (...), quando preciso mudar, venho para casa e a minha filha trata de mim" (E10). "A minha mulher faz isso muito bem" (colocação do dispositivo) (E13).

As mulheres tentam manter essa atividade como sua, numa tentativa provável de preservar a intimidade. Quando dependentes, recebem ajuda de filhas ou amigas, não referindo apoio do cônjuge. Nessa análise, além das questões culturais, devemos considerar também a viuvez ou a idade avançada dos cônjuges.

A perda de controle da eliminação de fezes e gases pode conduzir ao isolamento psicossocial, à alteração da identidade e autoestima, a sentimentos de desprestígio social e de incapacidade na gestão da situação ${ }^{(11-13)}$. "Deixei de fazer aquilo 
que mais gostava, fazer longos cursos de táxi, (...) Agora, nos sentimos dependentes daquilo que não era a nossa vida normal" (E13). A restrição de convívios e viagens está presente em todos os discursos, bem como a necessidade de condições adequadas para a troca de dispositivos e encobrimento da situação: "As minhas saídas agora são curtas, por causa dos gases, e tenho medo que o saco descole. Só na minha casa é que me sinto à vontade. (...) Ninguém gosta de dizer que tem saco" (E5).

A manipulação da informação social ou ocultação do defeito/ diferença constitui, na perspetiva de Goffman ${ }^{(14)}$, uma estratégia de preservação da identidade pessoal; no entanto, é geradora de tensão no exibir ou ocultar, revelar ou não a existência do estoma, a quem, quando, como e onde. Quando há incongruência entre os padrões ou estereótipos sociais e a pessoa, ela é olhada pela sociedade e por ela própria como algo estranho, anormal e diminuído, conduzindo à estigmatização, considerando a diferença como algo indesejável e ocultável. O estigma e seus significados, como construção da identidade pessoal e social, veem a pessoa desacreditável como sendo portadora de algo diferente (colostomia), que "não está imediatamente aparente e não se tem dele conhecimento prévio ou, pelo menos, ela não sabe que os outros a

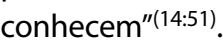

É notória a identificação do saco coletor como símbolo do ostomizado, ao representar a extensão do próprio corpo e permitir a materialização da vivência do corpo alterado(15), despojando-o do controle de gases e fezes que teimam em testemunhar sua presença: "Este saco (bolsa a tiracolo) é o espelho da minha doença, acompanha-me para todo o lado, (...) faz parte de mim" (E4).

Apenas um participante de 50 anos abordou as alterações de sua sexualidade, manifestando um grande sentido de revolta e perda: revolta pela informação ambígua e pouco esclarecedora, fornecida antes e após a cirurgia, que o levou a criar expectativas que não se confirmaram; perda porque as alternativas disponíveis não foram as mais satisfatórias: "Essa situação é traumatizante, ter que recorrer à injeção... não é bom. Deram-me outras esperanças" (E4).

Com efeito, uma ostomia abdominal pode causar alterações na fisiologia da função sexual, levando à impotência ou diminuição da libido, além da preocupação com a aceitação e satisfação do companheiro ${ }^{(11,12)}$.

Os resultados de alguns estudos revelam dificuldades na abordagem dessas questões pelos ostomizados e pelos enfermeiros $^{(11-13)}$. Apontam a influência prejudicial dos constructos culturais e estereótipos das pessoas e dos profissionais, pelo que é premente um novo olhar e uma maior valorização da(s) sexualidade(s) nos adultos e gerontes.

Percepciona-se um discurso comum quanto à organização de sua história de vida, aparecendo como que estruturada em duas etapas: o antes e o após a colostomia, evento que determina as perdas e modificações em relação à fase anterior.

Percebemos que alguns colostomizados já conseguiram construir o significado das perdas, quando verbalizam uma certa adaptação, possivelmente pelo tempo que decorreu após a cirurgia, suporte social, evolução da doença e tipo de estratégias de coping: "Comecei a cozinhar para me sentir útil. Agora vou abrir um restaurante com um amigo (E4); Já me habituei. Saber que estou vivo e que todos os exames estão bem" (E9).

Para a pessoa com ostomia, é importante manter uma atitude de esperança realista e dar-se tempo para se ajustar. Por outro lado, outros elementos da família e conviventes significativos podem também ter as próprias preocupações e receios, que, se forem partilhados, poderão ajudar-se mutuamente.

\section{Respostas das redes de suporte social e de saúde}

O universo vivido pela pessoa com colostomia depende de variáveis internas, mas também de uma rede de suporte sustentada na família, amigos, grupos de apoio social, profissionais de saúde e outros. $\mathrm{Na}$ maioria dos testemunhos, predomina o recurso a redes informais de apoio (família e amigos) como suporte para aumentar a resiliência e melhorar a aceitação e adaptação à doença: "Foi importante falar com as pessoas que me mereciam confiança deram-me ânimo, também o fato de minha esposa ter enfrentado com pé firme a situação, me ajudou a enfrentar também" (E7).

0 recurso à espiritualidade/ religiosidade revela-se bastante comum, mesmo naqueles que "não eram muito crentes". Criando significados positivos, através da deposição de confiança no divino, na oração e promessas, essas pessoas parecem obter tranquilidade, fé, esperança no futuro e sentido de vida: "Nunca fui muito de igreja, mas a vida nos ensina que há algo lá em cima que se Ihe pedimos com fé?! Vejo agora a vida de outra maneira" (E2); "Foram ouvidas as minhas preces, senão, não estava aqui" (E17).

Estudos sobre os processos de adaptação às alterações de saúde têm revelado os efeitos positivos do uso do coping religioso, que, associado a uma reinterpretação positiva, proporciona mais força para a gestão da doença e melhora a saúde mental, o bem-estar e a satisfação com a vida(16).

Essa fé de natureza religiosa dirige-se para algo superior e sobrenatural que tudo pode, se assim quiser e merecermos. Desse modo, a religião pode produzir alívio no sofrimento, uma vez que permite mudanças nas representações subjetivas face à doença e ao crescimento pessoal, ao estimular a reflexão sobre o significado da vida, o modo como foi vivida e sua finitude. Um estudo realizado com um grupo de colostomizados veteranos de guerra concluiu 
que a religiosidade/espiritualidade, além de melhorar a qualidade de vida espiritual, pode auxiliar os enfermeiros na prestação de cuidados holísticos ${ }^{(17)}$, pelo que a abordagem e o trabalho dessa dimensão humana devem ser valorizados.

Outro fator decisivo é o acompanhamento continuado da enfermeira estomaterapeuta, que, como dito, poderá influenciar o conceito de ser colostomizado, a reconquista do sentido da vida, bem como a manutenção ou reestruturação das atividades sociais, trabalho e laser anteriores à cirurgia.

Relativamente à rede formal de apoio, esses doentes parecem não reconhecer às equipes dos Centros de Saúde (CS) saberes e competências para a prestação dos cuidados que necessitam, uma vez que são os próprios profissionais que os aconselham a ir ao hospital: "Não vou ao centro de saúde, porque não fazem bem o trabalho" (E3); "O golpe da operação sim. [... ] o saco nunca o viram, porque diziam: 'Isso não é conosco"'(E10). Os cuidados que necessitam pós-alta hospitalar são percepcionados como especiais, razões apontadas para continuarem a preferir o seguimento no hospital onde reside o saber técnico especializado (cirurgião e enfermeira estomaterapeuta).

$\mathrm{Na}$ opinião dos enfermeiros dos CS, esses doentes têm necessidades especiais (apoio emocional, aprendizagem sobre cuidar do estoma, alimentação e sexualidade), às quais não dão resposta satisfatória. Admitem que esses utentes experimentam sentimentos de incerteza, incapacidade e medo de rejeição, pelo que necessitam de uma relação de proximidade, flexibilidade, confiança e cumplicidade sustentada na escuta e privacidade, para o qual não se reconhecem bem preparados.
Defendem, por isso, um modelo de intervenção que passe pela criação da consulta de estomaterapia nos CS e melhor formação específica dos profissionais de enfermagem.

\section{CONCLUSÕES}

Ao pretender-se estudar as implicações de uma colostomia na vida das pessoas portadoras, verificamos que, na população estudada, predominam idosos que interpretam sua doença como grave ou mortal, apesar de a ostomia representar a esperança e o alívio da dor, para alguns.

A maioria dos participantes demonstrava capacidades para o autocuidado; no entanto, alguns assumem comportamentos dependentes após a ostomia.

Apesar da aparente adaptação ao estoma, continuam a experimentar sofrimento emocional, envolvendo, em alguns casos, respostas de raiva, não-aceitação, negação ou ocultação. O suporte informal e formal revelou-se um apoio importante para enfrentarem as adversidades.

O recurso aos CS parece não ser uma prioridade, porque não respondem a suas necessidades ou porque são os próprios profissionais que os aconselham a recorrer ao hospital.

Os enfermeiros dos cuidados primários reconhecem que essas pessoas têm necessidades especiais e sobretudo concordam que, para um atendimento de proximidade adequado, é necessário desenvolver competências na prestação de cuidados específicos e a criação da consulta de enfermagem em estomaterapia nos CS.

\section{Referências}

1. Borwell B. Continuity of care for the stoma patient: psychological

considerations. Br J Community Nurs. 2009;14(8):330-1.

2. Fulhan J. A guide to caring for patients with a newly formed stoma in the

acute hospital setting. Gastrointest Nurs. 2008;6(8):14-23.

3. Haugen VBD, Savik K. Perioperative factors that long-term adjustment to an

incontinent ostomy. J Wound Ostomy Continence Nurs. 2006;33(5):525-35.

4. Vala J. A análise de conteúdo. In: Metodologia das ciências sociais. $3^{\text {a }}$ ed.

Porto: Afrontamento; 1989. p. 101-26

5. Lessard-Herbert M, Goyette G, Boutin G. Investigação qualitativa,

fundamentos e práticas. Lisboa: Instituto Piaget; 1994. p. 107-22.

6. Globocan 2008. Colorectal Cancer Incidence and Mortality Worldwide in

2008 [Internet, ccitado em 2011 fev 10]. Disponível em: http://globocan.iarc.fr/

factsheets/cancers/colorectal.asp.

7. Alves LC. Correlação entre adaptação psicossocial à colostomia permanente

e a resposta psicológica ao câncer [Internet, citado em 2011 nov 13].

Disponível em http://www.unifest.br/dpsiq/polbr/ppm/orginal.

8. Menezes APS, Quintana JF. A Percepção do indivíduo estomizado quanto à

sua situação. RBPS. 2008;21(1):13-8.

9. Silva AL, Shimizu HE. O significado da mudança no modo de vida da pessoa

com estomia intestinal definitiva. Rev Latinoam Enferm. 2006;14(4):483-90.
10. Brown $\mathrm{H}$, Randle J. Living with a stoma: a review of the literature. J Clin

Nurs. 2005;14(1):74-81.

11. Kiliç E, Taycan O, Belli AK, Ozmen M. The effect of permanent ostomy on body image, self-esteem, marital adjustment, and sexual functioning. Turk J Psychiat. 2007; 18(4):302-10.

12. Schmidt C, Bestmann B, Lindemann H, Küchler T, Löhnert M, Kremer B. Quality of life and sexuality after surgery for rectal cancer-a follow-up study. Zentralbl Chir. 2005;130(5):393-9.

13. Hughes MK. Alterations of sexual function in women with cancer. Semin Oncol Nurs. 2005;24(2):91-101.

14. Goffman E. Estigma: notas sobre a manipulação da identidade deteriorada. $4^{\mathrm{a}}$ ed. Rio de Janeiro: LTC; 1988. p. 51-113.

15. Santos VL, Sawaia BB. A bolsa na mediação "estar ostomizado" - "estar profissional": análise de uma estratégia pedagógica. Rev Latinoam Enferm. 2000;8(3):40-50.

16. Tix AP, Frazier PA. The use of religious coping during stressful life

events: main effects, moderation and meditacion. J Consult Clin Psychol.

1998;66(2):411-22.

17. Barbutti RCS, Silva MCPS, Abreu MAL. Ostomia, uma difícil adaptação. Rev SBPH. 2008;11(2):27-39. 